\title{
First report of monepantel Haemonchus contortus resistance on sheep farms in Uruguay
}

\author{
América E Mederos ${ }^{1 *}$, Zully Ramos ${ }^{1}$ and Georgget E Banchero ${ }^{2}$
}

\begin{abstract}
Background: On two farms it was noted that after routine treatment with monepantel, fecal egg counts failed to drop. This was accompanied by lambs mortality due to Haemonchus contortus infection. The aim of this work was to evaluate the efficacy of monepantel to control gastrointestinal nematodes $(G I N)$ in two sheep farms, in Uruguay.

Findings: A Fecal Egg Count Reduction Test (FECRT) was subsequently performed at the Experimental Stations Glencoe of INIA Tacuarembó (Farm 1) and Sheep Unit of INIA La Estanzuela (Farm 2) using the World Association for the Advancement of Veterinary Parasitology guidelines. On Farm 1 the FECRT was performed using 6-8 month old Corriedale or Merino Dohne x Corriedale male lambs naturally infected with GIN. On day 0 pre-treatment, three groups of 15 lambs each were selected, blocked by fecal egg count level (FEC) and randomly assigned to one of the following: Group $0=$ untreated control, Group $1=$ treated with monepantel (Zolvix ${ }^{\oplus}$, Novartis Animal Health Inc.) from stock previously purchased; Group 2 = treated with monepantel from stock provided by the supplier, at the recommended dose of $2.5 \mathrm{mg} / \mathrm{kg}$ of body weight. Fecal samples were collected directly from the rectum from each lamb on day 0 and on day 9 post-treatment. On Farm 2, the FECRT was conducted on a group of 8 month old male lambs Milchschaff $x$ Finn. At this farm, 10 lambs were randomly allocated to be treated with monepantel (Group 1) and 10 lambs were randomly allocated to remain as untreated control (Group 0) using the same protocols as Farm 1.

On farm 1 the FECR was $0.0 \%(95 \% \mathrm{Cl}=0.0-49.0)$ and $42.0 \%(95 \% \mathrm{Cl}=0.0-75.0)$ for Group 1 and Group 2 respectively. For Farm 2, the FECR was $82.1 \%(95 \% \mathrm{Cl}=36.0$ - 99.0). Haemonchus spp was the resistant genus.
\end{abstract}

Conclusions: Poor effcicacy of monepantel in treating GIN parasites was demonstrated on both farms.

Keywords: Sheep, Monepantel, Anthelmintic resistance, Haemonchus contortus, Uruguay

\section{Findings}

\section{Background}

In Uruguay, ovine production plays a very important role in the economy. Parasitism due to gastrointestinal nematodes (GIN) is one of the most important health constraints affecting sheep rearing operations and its control has relied primarily on the use of chemical drugs. As a result, anthelmintic resistance (AR) is a wide-spread phenomenon amongst sheep farms in this country. A national survey conducted between 1994 and 1995 to quantify the prevalence of anthelmintic resistance (AR) in sheep GIN [1], revealed that benzimidazole (BZ), levamisole (LEV) and ivermectin (IVM) resistance was

\footnotetext{
*Correspondence: amederos@inia.org.uy

'Beef and Wool Program, National Research Institute for Agriculture (INIA), Ruta $5 \mathrm{Km}$ 386, Tacuarembó 45000, Uruguay

Full list of author information is available at the end of the article
}

present on $80 \%, 71 \%$ and $1.2 \%$ respectively, of the studied sheep farms $(n=252)$. Subsequently, several reports from different diagnostic laboratories established that the prevalence of AR continues to escalate. In 2005, results from a sample of 130 sheep farms revealed that $89 \%$ had resistance to IVM, $82 \%$ to LEV, $89 \%$ to closantel and $29 \%$ to moxidectin [2]. In both studies, Haemonchus sp and Trichostrongylus spp were the main genera reported as resistant.

After many years, a new class of anthelmintic, the amino-acetonitrile derivative monepantel (Zolvix, Novartis Animal Health Inc.) was developed for the control of GIN in sheep [3]. Monepantel was first available in New Zealand in 2009 and became commercially available in Uruguay in 2010. The first report of AR to monepantel was reported from New Zealand in 2013 as a 
lack of efficacy against Teladorsagia circumcincta and Trichostrongylus colubriformis in goats [4].

The objective of this study was to evaluate the suspicion of poor efficacy of monepantel against gastrointestinal nematodes on two sheep farms at the National Research Institute for Agriculture (INIA), in Uruguay.

\section{Methods}

\section{The studied farms}

The study was conducted at the Experimental Stations Glencoe of INIA Tacuarembó (Farm 1), and INIA La Estanzuela (Farm 2), Colonia, Uruguay. Farm 1 is an extensive sheep and cattle production farm, occupying 1300 ha and located southwest of Uruguay (32 00'24”S, $\left.57^{\circ} 08^{\prime} 01^{\prime} \mathrm{W}\right)$. The farm maintains three sheep flocks: Australian Merino $(\mathrm{n}=977)$, Corriedale $(\mathrm{n}=258)$ and Merino Dohne and their crosses $(n=883)$. The gastrointestinal parasite control program is based on fecal egg count monitoring and anthelmintic treatment when indicated by high fecal egg counts. History of monepantel use on this farm was investigated to describe possible risk factors present for development of AR.

Farm 2 is located in the southwest region of Uruguay $\left(34^{\circ} 19^{\prime} 57^{\prime \prime} \mathrm{S}, 57^{\circ} 40^{\prime} 07^{\prime \prime} \mathrm{W}\right)$ and is an intensive sheep production system ( $\mathrm{n}=2250$ to 2500 ) occupying 100 ha with one flock comprised of multiple breeds mainly Milchschaf, Finn, Texel and Polwarth. Gastrointestinal parasite control is based on FAMACHA scoring $[5,6]$ and targeted selective treatment of sheep scoring " 4 " or " 5 ". History of monepantel use on this farm was also investigated.

Multidrug AR (benzimidazole, levamisole, ivermectin and closantel) was diagnosed on both farms by FECRT performed on a routine base, with Haemonchus contortus being the main gastrointestinal nematode diagnosed (unpublished data).

Sheep trade between both farms has been rare.

\section{Fecal egg count reduction test}

Fecal egg count reduction tests (FECRT) were carried out using the World Association for the Advancement of Veterinary Parasitology (WAAVP) guidelines [7,8]. On Farm 1 at the initial visit designated day -6 (May $14^{\text {th }}$, 2014), a total of 123 Corriedale and Merino Dohne $\times$ Corriedale 6-8 month old castrated male lambs naturally infected with gastrointestinal nematodes and not having been treated with any anthelmintic in 30 days, were weighed and individual fecal samples were taken directly from the rectum. The samples were identified with ear tag number and transported refrigerated to the laboratory and processed immediately after arrival. Results were used to assign lambs to treatment groups.

On day 0 pre-treatment (May $20^{\text {th }}, 2014$ ), three groups of 15 lambs each were selected, blocked by fecal egg count level (FEC) and randomly assigned to one of the following:
Group $0=$ untreated control (G0), Group $1=$ treated with monepantel (Zolvix ${ }^{\circ}$, Novartis Animal Health Inc.) from stock previously purchased (G1); Group $2=$ treated with monepantel (Zolvix ${ }^{\oplus}$, Novartis Animal Health Inc.), from stock provided by the supplier (G2).

Lambs assigned to G1 and G2 were drenched orally using a syringe at the corresponding drug dose according to their body weight, while lambs from G0 received no treatment. At the same time, fecal samples were collected directly from the rectum from each lamb, placed in a plastic bag, sealed after air removal, identified with ear tag, placed in a cooler and transported to the lab.

On day 9 post-treatment (May $29^{\text {th }}, 2014$ ) a second fecal sample from all lambs was taken and transported following the same procedure previously described.

At Farm 2, the FECRT was conducted to evaluate five drugs, but here we will describe only the monepantel evaluation. For this purpose, eight month old male lambs Milchschaff $\times$ Finn were randomly selected $(n=20)$ and 10 were randomly allocated to remain untreated as a control (Group $=0)$ and 10 lambs were randomly allocated to be treated with monepantel $($ Group $=1)$. From here, everything was performed according to the protocol described above.

All samples were processed at INIA Tacuarembó Animal Health Laboratory. Fecal egg counts were performed using a modified McMaster technique [9] with a lower detection limit of 50 eggs per gram. Coprocultures were performed using pooled fecal samples: the pre-treatment sampling at day 0 (G0, G1 and G2 combined), and subsequently one for each group at the post-treatment sampling at day 9 . The cultures were placed at $27^{\circ} \mathrm{C}$ during 10 days and then transferred to Baermann apparatus, recovered after $24 \mathrm{~h}$ and kept refrigerated at $4^{\circ} \mathrm{C}$ until analysis using standard identification keys $[9,10]$.

\section{Analysis and results interpretation}

The formula described by Dash (1988) [11] was used to estimate flock FECR, based on arithmetic means fecal egg counts in controls $(\mathrm{C})$ and treated $(\mathrm{T})$ animals:

$$
\mathrm{FECR}=100 \times(1-[\mathrm{T} 2 / \mathrm{T} 1][\mathrm{C} 1 / \mathrm{C} 2]),
$$

and 95\% Confidence Intervals were estimated using the BootStreat program [12].

\section{Results}

Farm 1

At day -6 pre-treatment the mean FEC after sorting the groups were 3010, 3530 and 3717 eggs per gram and the mean body weight $29 \mathrm{~kg}, 27 \mathrm{~kg}$ and $28 \mathrm{~kg}$ for the lambs of G0, G1 and G2, respectively.

The results presented in Table 1, supports the hypothesis that monopantel lacks sufficient efficacy to reduce 
Table 1 Results of the mean fecal egg counts pre and post-treatment for all groups and \%FECR for the evaluated anthelmintic drugs and the $95 \%$ confidence intervals $(\mathrm{Cl})$

\begin{tabular}{llll}
\hline & $\begin{array}{l}\text { FEC Pre- } \\
\text { treatment }\end{array}$ & $\begin{array}{l}\text { FEC Post- } \\
\text { treatment }\end{array}$ & \%FECR (95\% CI) \\
\hline Farm 1 & &
\end{tabular}

\section{Farm 1}

$\begin{array}{llll}\text { G0 }=\text { Control } & 3307 & 5490 & \text { NA } \\ \text { G1 }=\text { Monepantel }^{1} \text { Lab } & 3020 & 5132 & 0.0(0.0-49.0) \\ \text { G2 }=\text { Monepantel New } & 5117 & 5114 & 42.0(0.0-75.0)\end{array}$

Farm 2

$\begin{array}{llll}\text { G0 }=\text { Control } & 6875 & 6345 & \text { NA } \\ \text { G1 }=\text { Monepantel Lab } & 2880 & 475 & 82.1(36.0-99.0)\end{array}$

FEC = fecal egg counts; \%FECR = percentage fecal egg counts reduction; $\mathrm{NA}=$ not applicable.

${ }^{1}$ Zolvix (Novartis Animal Health Inc.).

the FEC burden in the studied farms and that anthelmintic resistance to monepantel exists in that parasite population.

\section{Farm 2}

The results presented in Table 1, demonstrated that both the \%FECR and the 95\% confidence interval were below the limit established for adequate efficacy by the WAAVP guidelines. Results from coprocultures revealed that Haemonchus spp. was the main genus that developed in monepantel groups (see Table 2).

\section{History of Monepantel use}

Historical use of monepantel was considered retrospectively as a possible risk factor for development of anthelmintic resistance. On Farm 1, the first treatment with monepantel was given in March 2011 (autumn); a second treatment was given in August and a third in December to the whole ewe flocks. Subsequently, during 2012, a single drench was administered to all the lambs and all breeding ewes received two drenches (before lambing and nursing).
However, during 2013 the drug was used more frequently, being all lambs and all ewes the group that received three treatments based on fecal egg counts.

On Farm 2, monepantel use started in May 2011, but here sheep and lambs were selectively treated based on routine FAMACHA scoring for anemia and the proportion of the flock that required treatment varied from 5\% to $10 \%$. Paddocks management in both farms is very complex in comparison with commercial sheep farms, due to the various production and experimental trials performed. Therefore, retrospective unbiased results about potential causal factors could not be obtained.

\section{Discussion}

The results presented above demonstrated that on two farms, a multidrug resistant strain of Haemonchus contortus (unpublished observations) developed apparent resistance to monepantel as evidence by treatment failure assessed using a FECRT. Resistance to monepantel has also been reported in New Zealand [4,5], but in that case monepantel failed to control Teladorsagia circumcincta and Trichostrongylus colubriformis in goats. In New Zealand monepantel was licensed in 2009 and resistance was reported four years later, similar to what has now happened in Uruguay since monepantel was licensed in 2010 and resistance detected in 2014. Previous research has demonstrated an AAD mutant gene present in a sub-population of $H$. contortus $[3,13]$. The results of this investigation support the presence of this gene in the field through its apparent phenotypic expression on these two farms. To confirm the presence of this gene, Haemonchus spp. isolates from the coprocultures and adult worms would need to be further examined. In addition to the FECRT, other methods to detect multidrug anthelmintic resistence might be explored, as recently proposed by Roeber et al. [14].

On both Farm 1 and Farm 2, the frequency of monepantel use was low prior to experiencing apparent treatment

Table 2 Results of the percentage of gastrointestinal nematodes genera identified from the coprocultures at both farms

\begin{tabular}{|c|c|c|c|c|}
\hline Group & Time & Haemonchus sp. \% & Trichostrongylus sp. \% & Oesophagostumum sp. $\%$ \\
\hline \multicolumn{5}{|l|}{ Farm 1} \\
\hline Control & Day 0 & 86 & 11 & 3 \\
\hline Control & Day10 & 92 & 7 & 1 \\
\hline Monepantel ${ }^{1}$ Lab & Day 10 & 100 & 0 & 0 \\
\hline Monepantel New & Day10 & 100 & 0 & 0 \\
\hline \multicolumn{5}{|l|}{ Farm 2} \\
\hline Control & Day 0 & 4 & 85 & 11 \\
\hline Control & Day10 & 28 & 52 & 20 \\
\hline Monepantel Lab & Day10 & 93 & 3 & 4 \\
\hline
\end{tabular}

'Zolvix (Novartis Animal Health Inc.). 
failure. High frequency of treatments and lack of population in refugia are the main risk factors for AR development most commonly incriminated in the literature. Based on the history available, these factors do not seem to be important here. As mentioned above, on Farm 1, monepantel was seldom used from 2011 to 2012 and applied three times to all animals from the same flock during 2013. On Farm 2, all treatments were applied using targeted selective treatment based on FAMACHA scoring, thus not eliminating refugia due to massive treatment. This is in concordance with a recent study that highlighted the lack of unbiased scientific evidence for risk factors associated with the development of AR in sheep gastrointestinal nematodes [15].

\section{Conclusions}

The present situation of anthelmintic resistance in Uruguay is becoming aggravated with the early development of resistance to monepantel by Haemonchus spp. (putative Haemonchus contortus). Further molecular studies are necessary to understand the mechanism of monepantel resistance, allowing early detection to develop strategies to prevent the spread of resistant worms.

\section{Competing interests}

The authors declare that they have no competing interests.

\section{Authors' contribution}

AEM and GEB were responsible for FECRT process and prepared the manuscript. ZR coordinated field activities at Farm 1 and provided data on drug use. All authors read, revised and approved the final manuscript.

\section{Acknowledgments}

We are very grateful to field personnel from INIA Research Farms "Glencoe" and La Estanzuela. We thank S. Pimentel, B. Carracelas and L. Moreno for laboratory work We thank Dr. Paula Menzies for language editing and critical review of the manuscript.

\section{Author details \\ ${ }^{1}$ Beef and Wool Program, National Research Institute for Agriculture (INIA), Ruta $5 \mathrm{Km}$ 386, Tacuarembó 45000, Uruguay. ${ }^{2}$ Beef and Wool Program, National Research Institute for Agriculture (INIA), La Estanzuela, Ruta 50 Km 11, Colonia, Uruguay.}

Received: 29 August 2014 Accepted: 9 December 2014

Published online: 17 December 2014

\section{References}

1. Nari A, Salles J, Gil A, Waller PJ, Hansen JW: The prevalence of anthelmintic resistance in nematode parasites of sheep in southern Latin America: Uruguay. Vet Parasitol 1996, 62:213-222.

2. Mederos A, Gallinal M, González H, Silva L, Rodriguez S: Diagnóstico de resistencia a los antihelmínticos en ovinos en Uruguay. In Resumen del $12^{\circ}$ Simposio Internacional de la Asociación Mundial de Laboratorios de Diagnóstico Veterinario (WAVLD). Montevideo, Uruguay: Sociedad de Medicina Veterinaria del Uruguay 2005.

3. Kaminsky R, Ducray P, Jung M, Clover R, Rufener R, Bouvier J, Schorderet Weber S, Wenger A, Wieland-Berghausen S, Goebel T, Gauvry N, Pautrat F, Skripsky T, Froelich O, Komoin-Oka C, Westlund B, Sluder A, Mäser P: A new class of anthelmintic effective against drug-resistant nematodes. Nature 2008, 452:176-180.

4. Scott I, Pomroy B, Paul K, Greg S, Barbara A, Moss A: Lack of efficacy of monepantel against Teladorsagia circumcincta and Trichostrongylus colubriformis. Vet Parasitol 2013, 198:166-171.
5. Van Wyk JA, Bath GF: The FAMACHA system for managing haemonchosis in sheep and goats by clinically identifying individual animals for treatment. Vet Res 2002, 33:509-529.

6. Vatta AF, Letty BA, van der Linde MJ, Krecek RC: Testing of a chart for the diagnosis of ovine clinical anaemia caused by haemonchosis for use in goats farmed under resource-poor conditions in South Africa. In FAO TCP Workshop on Sustainable Worm Control Programmes for Sheep and Goats. Edited by Anonymous. Pretoria, South Africa: Faculty of Veterinary Science, University of Pretoria; 2000

7. Coles GC, Bauer C, Borgsteede FHM, Geerts S, Klei TR, Taylor MA, Waller PJ: World Association for the Advancement of Veterinary Parasitology (W.A.A.V.P.) methods for the detection of anthelmintic resistance in nematodes of veterinary importance. Vet Parasitol 1992, 44:35-44.

8. Coles GC, Jackson F, Pomroy WE, Prichard RK, von Samson-Himmelstjerna G, Silvestre A, Taylor MA, Vercrsuysse J: The detection of anthelmintic resistance in nematodes of veterinary importance. Vet Parasitol 2006, 136:167-185.

9. Ministry of Agriculture, Fisheries, Food (MAFF): Manual of Veterinary Parasitological Laboratory Techniques. London: Ministry of Agriculture, Fisheries and Food; 1986.

10. Van Wyk JA, Mayhew E: Morphological identification of parasitic nematode infective larvae of small ruminants and cattle: A practical lab guide. Onderstepoort J Vet Res 2013, 80:1-14. doi:10.4102/ojvr.v80i1.539.

11. Dash K, Hall K, Barger IA: The role of arithmetic and geometric worm egg counts in faecal egg count reduction test and in monitoring strategic drenching programs in sheep. Aust Vet J 1988, 65:66-68.

12. Cabaret J, Antoine T: In Anthelmintics. Clinical Pharmacology, uses in veterinary medicine and efficacy. W. Quick Ed. Nova, New York: Nova science publisher; 2014. p. 1-26.

13. Rufener L, Mäser P, Rodit I, Kaminsky R: Haemonchus contortus acetylcholine receptors of the DEG-3 subfamily and their role in sensitivity to monepantel. PLos Pathogens 2009, 5:1-11.

14. Roeber F, Jex AR, Gasser RB: Impact of gastrointestinal parasitic nematodes of sheep, and the role of advanced molecular tools for exploring epidemiology and drug resistance - an Australian perspective. Parasit Vectors 2013, 6:153.

15. Falzon LC, O'Neill TJ, Menzies Pl, Peregrine AS, Jones-Bitton A, van Leeuwen $J$, Mederos A: A systematic review and meta-analysis of factors associated with anthelmintic resistance in sheep. Prev Vet Med 2014, 17:388-402.

\section{Submit your next manuscript to BioMed Central and take full advantage of:}

- Convenient online submission

- Thorough peer review

- No space constraints or color figure charges

- Immediate publication on acceptance

- Inclusion in PubMed, CAS, Scopus and Google Scholar

- Research which is freely available for redistribution 